\title{
A ORIENTAÇÃO ARGUMENTATIVA DOS MODALIZADORES AVALIATIVOS
}

\section{Francisca Janete da Silva Adelino ${ }^{i}$ Erivaldo Pereira do Nascimentoii}

\begin{abstract}
Resumo: Este estudo analisa a orientação argumentativa dos modalizadores avaliativos em entrevistas de seleção de emprego, adotando a concepção de argumentação como orientação discursiva, proposta por Ducrot (1988) e colaboradores, mas fundamenta-se, principalmente, nos estudos sobre a modalização discursiva, a partir de diferentes autores. Apresenta uma natureza qualitativa, de caráter descritivo e de base interpretativa. De modo mais preciso, orienta-se pelas seguintes questões: (i) que modalizadores avaliativos são usados na construção do gênero entrevista de seleção de emprego?; e (ii) como tais modalizadores avaliativos são mobilizados de modo a construir a argumentatividade nas/das entrevistas? A análise realizada no corpus, constituída por 22 entrevistas de seleção de emprego, constatou a mobilização de adjetivos, advérbios, expressões adverbiais, orações adjetivas, entre outros elementos linguísticos, funcionando como modalizadores discursivos no gênero em estudo, orientando argumentativamente os enunciados, no sentido de expressar juízos de valor ou apresentar uma justificativa a respeito do conteúdo proposicional.
\end{abstract}

Palavras-chave: Modalização avaliativa. Argumentação. Entrevista de seleção de emprego.

\begin{abstract}
This investigation analyses the argumentative orientation throughout evaluative modalizers of job interviews. It is based on the conception of argumentation as discursive orientation, proposed by Ducrot (1988) and his collaborators, but it is mainly based on the studies of discoursive modalization, proposed by different authors. It is a qualitative and descriptive investigation with an interpretative analysis. Specifically, it tries to answer the following questions: i) which evaluative modalizers are used to compose the job interview genre? and ii) how these evaluative modalizers are employed so as to produce argumentation in job interviews? The corpus was composed by 22 job interviews. The analysis of the corpus demonstrated the use of adjectives, adverbs and adjective-clauses working as discursive modalizers, in the genre, in order to create argumentative orientation in the sentences and also to express judgments or points of view or to introduce a justification about the propositional content.
\end{abstract}

Keywords: Evaluative modalization. Argumentation. Job interview genre.

i Professora Doutora da Universidade Federal da Paraíba (UFPB). E-mail: janete_adelino@hotmail.com. ii Professor Doutor do Programa de Pós-Graduação em Linguística e do Mestrado Profissional em Letras da Universidade Federal da Paraíba (UFPB). E-mail: rypn@hotmail.com. 
EID\&A - Revista Eletrônica de Estudos Integrados em Discurso e Argumentação, Ilhéus, n. 13, jan/jun.2017.

\section{Introdução}

Este estudo' objetiva descrever e analisar o funcionamento linguísticodiscursivo dos modalizadores avaliativos, enquanto elementos que materializam a argumentatividade no gênero entrevistas de seleção de emprego. Assim, busca responder às seguintes questões: (i) que modalizadores avaliativos são usados na construção do gênero entrevista de seleção de emprego?; e (ii) como tais modalizadores avaliativos são mobilizados de modo a construir a argumentatividade nas/das entrevistas? Convém ressaltar, no entanto, que este trabalho é parte de uma investigação realizada no âmbito do nosso doutoramento em Linguística, que objetivou, entre outros aspectos, investigar a argumentatividade no gênero entrevista de emprego, principalmente através da mobilização de diferentes modalizadores discursivos.

A investigação adota a concepção de argumentação de Ducrot (1988) e colaboradores, para quem a língua é por natureza argumentativa. A argumentação, nessa perspectiva, não é vista apenas como uma habilidade para persuadir e convencer, mas, principalmente, como orientação discursiva. Nesse sentido, mobiliza diferentes elementos linguísticos, entre os quais os modalizadores discursivos, conforme sugerem Koch (2010) e Nascimento \& Silva (2012).

A modalização discursiva é vista, neste trabalho, como um fenômeno semântico-argumentativo e pragmático que, na perspectiva de Nascimento \& Silva (2012), se materializa, no discurso, por meio da mobilização de diferentes elementos e fenômenos linguístico-discursivos (verbos modais, adjetivos e advérbios modalizadores, verbos dicendi modalizadores, entonação, entre outros). Esses elementos e fenômenos, denominados de modalizadores discursivos, orientam argumentativamente os enunciados em razão de determinadas conclusões. Além dos estudos de Nascimento \& Silva (2012), utilizou-se também os postulados de Castilho \& Castilho (2002) e Koch (2010), no que se refere ao funcionamento dos modalizadores discursivos nos enunciados.

Ademais, mobiliza noções advindas do Círculo de Bakhtin (2011 [1979]), uma vez que compreende a entrevista de seleção de emprego a partir da concepção de gêneros discursivos. Convém ressaltar ainda que o gênero

\footnotetext{
1 Este estudo apresenta dados da tese de doutorado de Adelino (2016): Na trilha dos modalizadores: perscrutando os jogos argumentativos no gênero entrevista de seleção de emprego.
} 
EID\&A - Revista Eletrônica de Estudos Integrados em Discurso e Argumentação, Ilhéus, n. 13, jan/jun.2017.

pesquisado circula na área da Administração de Empresas. Com isso, a pesquisa não só desvenda os modalizadores recorrentes no gênero entrevista de seleção de emprego, contribuindo para os estudos linguísticos sobre os gêneros discursivos, mas, também, oferece uma contribuição teórica, prática e social para a área da administração, no sentido de revelar como se dá o uso e o funcionamento do gênero pesquisado.

Tomando-se como base a noção de argumentação proposta por Ducrot (1988), juntamente com a concepção bakhtiniana de linguagem, percebe-se a orientação argumentativa dos elementos linguísticos, considerando-se que tais elementos são mobilizados na troca comunicativa, ou seja, na relação dialógica entre sujeitos situados em esferas sociais (BAKHTIN, 2011 [1979]).

O estudo de um fenômeno como a modalização, por exemplo, que se realiza em situações de interação entre os usuários da língua, requer que se considere a língua em uso. Ou seja, não apenas a estrutura linguística, mas, também, a situação comunicativa, o propósito do evento da fala, seus participantes e seu conteúdo discursivo. Essa postura diante das ocorrências de linguagem, assume que "o emprego da língua efetua-se em forma de enunciados (orais e escritos), concretos e únicos, que emanam dos integrantes duma ou doutra esfera da atividade humana" (BAKHTIN, 2011 [1979], p. 261). Esses enunciados refletem as condições e as finalidades de cada uma das esferas sociais.

Dito isso, no tocante aos aspectos metodológicos, a presente pesquisa se insere nos postulados da Semântica Argumentativa, especialmente nos estudos sobre a Modalização Discursiva e na concepção de argumentação defendida pela Teoria da Argumentação na Língua, de Ducrot (1988) e colaboradores. E assume uma natureza qualitativa, de caráter descritivo e de base interpretativa. Quanto ao material examinado - as entrevistas de seleção de emprego -, este ainda não recebeu um tratamento analítico, o que faz com que o presente trabalho se configure como uma pesquisa documental também. $O$ corpus é composto por vinte e duas (22) entrevistas de seleção de emprego, gravadas em um Centro Universitário do Estado do Rio Grande do Norte $^{2}$, na cidade de Natal - RN.

\footnotetext{
${ }^{2}$ O nome do Centro Universitário no qual realizamos a coleta do nosso corpus não será revelado tendo em vista o compromisso que assumimos junto ao Conselho de Ética. Assim, usaremos o nome fictício denominado de Unixy.
} 
EID\&A - Revista Eletrônica de Estudos Integrados em Discurso e Argumentação, Ilhéus, n. 13, jan/jun.2017.

A Teoria da Argumentação na Língua tem servido de base para ancorar diversas investigações cujo propósito é discutir aspectos argumentativos essenciais para a compreensão do sentido do texto e do discurso. Essas investigações têm contribuído principalmente para ampliar o entendimento a respeito do funcionamento da língua não apenas como estrutura, mas também enquanto prática social de interação verbal $(\mathrm{KOCH}, 2010)$.

No próximo tópico, serão apresentadas breves notas conceituais acerca da modalização, focalizando a modalização avaliativa. Logo depois, serão discutidos os achados desta pesquisa, a partir da análise de ocorrências extraídas do corpus. Por fim, nas considerações finais, serão destacados alguns resultados considerados relevantes.

\section{Da Modalização à Modalização Avaliativa/afetiva}

De início, cabe esclarecer que há autores que distinguem os conceitos de modalidade e modalização, mas há quem os empregue como sinônimos. Entre os que fazem distinção podemos citar Castilho \& Castilho (2002, p. 201). Estes autores explicam que o primeiro conceito - modalidade - ocorre quando "o falante apresenta o conteúdo proposicional numa forma assertiva (afirmativa ou negativa), interrogativa (polar ou não-polar) e jussiva (imperativa ou optativa)". Já o segundo conceito - modalização - tem sido usado quando "o falante expressa seu relacionamento com o conteúdo proposicional" (CASTILHO; CASTILHO, 2002, p. 201). Entre os pesquisadores que não estabelecem distinção entre os conceitos supracitados, encontra-se Nascimento (2005), por exemplo, que emprega os termos modalidade e modalização sinonimamente. Diante desses dois posicionamentos, a presente pesquisa adota este último, ou seja, utiliza os termos modalidade e modalização de forma equivalente.

Feito esse esclarecimento inicial, destaca-se que todo enunciado apresenta uma marca de avaliação por parte do locutor. Neves (2011) postula que, em cada enunciado, atribui-se uma atitude modal. Essa natureza do enunciado não tem, conforme a autora, recebido o tratamento merecido por parte da tradição linguística. Ao discorrer sobre os modalizadores que marcam a modalização, a autora diz que eles se apresentam por uma diversidade de formas.

A atitude modal deixa suas marcas no próprio enunciado. Acerca desse aspecto, Castilho \& Castilho (2002) entendem que a modalização é um fenômeno da linguagem que expressa um julgamento do falante sobre o 
EID\&A - Revista Eletrônica de Estudos Integrados em Discurso e Argumentação, Ilhéus, n. 13, jan/jun.2017.

conteúdo proporcional. Os elementos linguísticos que materializam a modalização, nos enunciados, são denominados de modalizadores. Esses elementos são agrupados, conforme os estudiosos citados, em três tipos de modalização: Epistêmica, Deôntica, e Avaliativa/Afetiva. O primeiro tipo se dá no eixo do conhecimento e está relacionada à necessidade e à possibilidade epistêmica e, nesse tipo de modalização, o locutor expressa uma avaliação sobre o caráter de certeza do conteúdo do enunciado. O segundo, (modalização deôntica), se dá no eixo da conduta e, nele, o locutor expressa uma avaliação sobre o caráter facultativo, proibitivo, volitivo ou de obrigatoriedade. $O$ terceiro tipo (modalização avaliativa/afetiva), expressa uma avaliação ou ponto de vista sobre o conteúdo, excetuando-se qualquer caráter epistêmico ou deôntico. Este terceiro tipo representa o foco deste artigo.

A modalização avaliativa - também denominada de modalização afetiva -verbaliza as reações emotivas do falante em face do conteúdo proposicional, deixando de lado quaisquer considerações de caráter epistêmico ou deôntico (CASTILHO; CASTILHO, 2002). Esse tipo de modalização pode ser marcado por predicadores como "eu sinto $\mathrm{X}$ em face de $\mathrm{P}$ ".

Tal modalização se subdivide em dois tipos, quais sejam, (i) subjetivos: expressam uma predicação dupla, a do falante em face da proposição (P), e a da própria proposição por meio de modalizadores como felizmente, infelizmente, curiosamente, surpreendentemente, espantosamente; (ii) intersubjetivos: "expressam uma predicação simples, assumida pelo falante em face de seu interlocutor, a propósito de $\mathrm{P}$, como em sinceramente, francamente, lamentavelmente, estranhamente" (CASTILHO; CASTILHO, 2002, p. 208).

Castilho \& Castilho (2002) citam alguns exemplos de ocorrências desse tipo de modalização: (1) infelizmente Recife é uma cidade de mais de um milhão de habitantes; (2) felizmente estou muito contente com isso... vivo num ambiente sadio... gosto de conviver com os meus discípulos; (3) sinceramente... não consegui... não consegui entender; (4) francamente... esta reunião já me cansou.

Ao lançar mão de modalizadores avaliativos/afetivos, o locutor se envolve emocionalmente com o conteúdo da proposição. Nesse caso, o locutor expressa seus sentimentos diante da proposição - modalizadores avaliativos subjetivos - e/ou assume uma posição avaliativa diante do interlocutor em face da proposição - modalizadores avaliativos intersubjetivos. Assim, nos dizeres de Castilho \& Castilho (2002, p. 238), 
EID\&A - Revista Eletrônica de Estudos Integrados em Discurso e Argumentação, Ilhéus, n. 13, jan/jun.2017.

"nesse caso de modalização, tematizam-se os interlocutores e, secundariamente, a proposição, gerando um efeito polifônico”.

Na mesma perspectiva, Nascimento (2005) argumenta que esse tipo de modalização, mais do que revelar um sentimento ou emoção por parte do locutor, em função da proposição do enunciado, "indica uma avaliação da proposição por parte do falante, emitindo juízo de valor, e indicando, ao mesmo tempo, como o falante quer que essa proposição seja lida" (NASCIMENTO, 2005, p. 64).

Segundo o autor, esse tipo de modalização permite observar como o locutor imprime no enunciado um juízo de valor; uma avaliação a respeito do conteúdo proposicional. O referido pesquisador menciona a modalização como um fenômeno complexo, inerente à interação, presente em diferentes gêneros discursivos, que veicula argumentatividade e que também se constitui num ato particular de linguagem.

$\mathrm{Na}$ investigação desenvolvida por Nascimento \& Silva (2012, p. 88), constata-se a seguinte explicação: “[...] a modalização avaliativa é aquela em que um locutor expressa um juízo de valor a respeito do conteúdo do enunciado, excetuando-se qualquer avaliação de caráter deôntico ou epistêmico". Para os estudiosos, é através dos modalizadores, como advérbios, que o locutor emite uma avaliação e um juízo de valor com relação ao conteúdo do enunciado.

Além disso, quanto ao aspecto argumentativo, os modalizadores avaliativos também expressam uma avaliação por parte do locutor em relação ao interlocutor, ou seja, o locutor produz determinado enunciado direcionandoo para seu interlocutor, indicando como este deve ler tal enunciado.

Após esse breve apanhado teórico-conceitual, no tópico seguinte, retomase o corpus deste estudo, focalizando o uso dos modalizadores avaliativos na construção argumentativa nas/das entrevistas de seleção de emprego.

\section{A orientação argumentativa da Modalização Avaliativa (MAV) na construção de entrevistas de seleção de emprego}

Nas análises empreendidas, a modalização avaliativa é marcada em pontos da entrevista em que o locutor expressa seu juízo de valor ou apresenta uma justificativa a respeito do conteúdo proposicional, excetuandose qualquer avaliação de caráter deôntico ou epistêmico. Os trechos a seguir 
EID\&A - Revista Eletrônica de Estudos Integrados em Discurso e Argumentação, Ilhéus, n. 13, jan/jun.2017.

mostram a mobilização de adjetivos, advérbios, expressões adverbiais, orações adjetivas funcionando como modalizadores avaliativos na construção da argumentatividade no/do gênero entrevista de seleção de emprego.

\begin{abstract}
MAVo9-EE01-Linhas 94-98 3
L1[...] então... eu tô eu tô dizendo o nosso... a nossa postura... AQUI nos temos uma estrutura... boa estrutura... é é suporte necessário ao professor... é tudo registrado... carteira assinada... tudo assinado direitinho... e mas aí sempre vem a pergunta... você tem um currículo muito bom... mas... o que lhe atraiu pra docência mesmo?
\end{abstract}

No trecho MAVog da EE01, $\mathrm{L}^{4}$ constrói seu discurso usando argumentos que ressaltam os pontos positivos tanto a respeito das condições de trabalho oferecidas pela Unixy, quanto para emitir elogios acerca do currículo do candidato entrevistado. Em favor dessa valorização, L1 estabelece uma relação dialógica com L25 ${ }^{5}$, visando levá-lo a aderir a esses pontos de vista. Podemos perceber que L1 se engaja ao falar sobre a instituição, expressando sua atitude de valoração e de orgulho pela Unixy. Para isso, ele faz uso de recursos linguísticos que funcionam argumentativamente na construção de uma imagem positiva da instituição.

No caso em análise, a orientação argumentativa é materializada por meio dos modalizadores avaliativos, destacados em itálico, os quais sinalizam o ponto de vista de L1 diante das condições de trabalho que a Unixy oferece para o seu corpo docente tanto em termos de infraestrutura, quanto em relação à segurança trabalhista, considerando que é tudo registrado... carteira assinada... tudo assinado direitinho... Assim, a escolha desses elementos linguísticos evidencia o esforço do locutor em fortalecer a imagem da Unixy.

Ademais, L1, ao conduzir os tópicos da entrevista, entra no objetivo principal que é questionar L2 acerca da docência, deixando implícito que L2 poderia atuar, por exemplo, em outros níveis tais como graduação ou pósgraduação, considerando que $L 2$ [...] tem um currículo muito bom... [...]. Assim, nessa parte da entrevista, a expressão avaliativa muito bom exalta o currículo do entrevistado, constituindo-se em um verdadeiro julgamento positivo que L1 faz a respeito das qualificações de L2; por esse motivo, funciona como um

\footnotetext{
3Utilizamos essa codificação para identificar os modalizadores (MAVog - Modalizador Avaliativo 09), as entrevistas de seleção de emprego (EE01 - Entrevista de Emprego 01) e as linhas da entrevista transcrita em que se encontra o trecho reproduzido (Linhas 94-98).

${ }^{4}$ L1 é o entrevistador responsável por conduzir a entrevista.

${ }^{5}$ L2 é o entrevistado que concorre a vaga de professor na Unixy.
} 
EID\&A - Revista Eletrônica de Estudos Integrados em Discurso e Argumentação, Ilhéus, n. 13, jan/jun.2017.

elemento modalizador avaliativo. Conforme afirma Nascimento \& Silva (2012), o modalizador avaliativo não só serve para que o locutor imprima seu ponto do vista no enunciado mais também serve para indicar como o interlocutor deve ler esse enunciado. Dessa forma, a modalização avaliativa "é aquela em que um locutor expressa um juízo de valor a respeito do conteúdo do enunciado" (NASCIMENTO; SILVA, 2012, p. 88).

Portanto, a expressão muito bom revela o ponto de vista de L1 sobre o fato de L2 possuir um bom currículo. Voltando ao enunciado como um todo, percebese que o efeito de sentido produzido pela combinação dos elementos modificadores (boa, necessário, direitinho e muito bom), orientam argumentativamente os enunciados em que aparecem em razão de determinada conclusão, acrescentando força argumentativa ao discurso: Especificamente, o uso desses elementos coloca estrategicamente L2 como responsável por fazer a escolha de assumir um contrato de trabalho, caso seja selecionado.

\footnotetext{
MAV11-EE01-Linhas 104-110

L2 então... eu SEMpre me senti muito à vontade [...]

L1 vocês dão aula nesse período que depois eu vejo ((riu))..

L2 é:: sempre me senti muito à vontade muito bem em relação a isso... na Usp eu também fiz dois estágios pra docência... um na faculdade de veterinária e um na fisioterapia... na área de farmacologia... e eu gostei assim... particularmente... eu me sinto bem à vontade quando eu tô em sala de aula...
}

No trecho MAV11 da EE01, a modalização avaliativa se materializa no discurso de L2 por meio das expressões muito à vontade que incide, semanticamente, sobre SEMpre me senti e confere ao enunciado a forma como L2 se sente na condução da sala de aula, ou seja, ele se sente confortável atuando como professor. Em seguida, repete a mesma expressão muito à vontade seguida da expressão muito bem para reforçar o seu argumento. Continuando o discurso, faz uso do verbo gostar para registrar a sua preferência pela área de farmacologia e, mais adiante, lança mão de uma quarta expressão avaliativa bem à vontade, que incide sobre o segmento quando eu tô em sala de aula..., construindo a imagem de um profissional que se sente confortável no seu trabalho. Essa orientação argumentativa é construída em relação ao interlocutor ( $L 1)$.

Em outras palavras, a avaliação feita por L2 em relação à sua própria prática revela uma imagem positiva ao transmitir a noção de que é um profissional que gosta do que faz e se apresenta como um candidato comprometido com a profissão. Ao tecer esse argumento, L2 faz uma auto- 
EID\&A - Revista Eletrônica de Estudos Integrados em Discurso e Argumentação, Ilhéus, n. 13, jan/jun.2017.

avaliação sobre o fato de ele ter, entre outros atributos, vocação pela área docente, motivo pelo qual se julga hábil a ser aprovado na seleção para assumir a disciplina de Radiologia Veterinária na Unixy.

Assim, constata-se o jogo argumentativo entre L2 e L1, a partir da orientação argumentativa que é dada à linguagem, através do uso dos modalizadores discursivos em destaque, utilizados no processo interacional para expressar desejos e intenções, nos termos em que postula Koch (2011). Para essa pesquisadora, nós "procuramos dotar nossos enunciados de determinada força argumentativa", para atuar sobre o outro por meio da linguagem (KOCH, 2010, p. 29).

Nesse sentido, no gênero discursivo entrevista de seleção de emprego ocorre aquilo que Bakhtin (2011 [1979]) denomina de a compreensão de uma fala viva, ou seja, na interação viva, um enunciado é sempre acompanhado de uma atitude responsiva ativa. Na linha de pensamento desse estudioso, na troca dialógica, todos os enunciados nascem como respostas e, consequentemente, aquele que era ouvinte torna-se locutor. Logo, nesse tipo de interação que ocorre durante a entrevista, o par locutor x ouvinte não é estanque, mas tais posições mudam constantemente.

Nessa perspectiva, a entrevista é construída a partir do "consenso entre indivíduos" e é, ao mesmo tempo, produzida por indivíduos. Enquanto gênero discursivo, ela tem uma natureza dialógica no sentido de ser o resultado do consenso entre sujeitos socialmente situados.

\footnotetext{
MAV18- EE01-Linhas 188-193

L1 [...] eu tenho alunos com mestrado... com cursos de pós-graduação... tenho alunos com duas ou três formaturas... mas também tenho aluno que passou QUINze VINte anos sem pegar numa caneta pra escrever nada... temos alunos que moram em situações... é:: que moram em assentamentos... eu tenho muitos problemas de horário com alunos que chegam atrasados porque dependem do ônibus da prefeitura... tenho alunos que são da extrema pobreza MESmo...
}

Neste trecho da EE01, L1 está relatando o perfil dos alunos que frequentam os cursos técnicos vinculados ao PRONATEC. Ele diz que há no curso de Radiologia Veterinária da Escola Técnica da Unixy alunos com uma boa base de conhecimento, com várias formaturas e também com pósgraduação. Mas há também alunos que estavam fora da universidade e voltaram a estudar somente agora, além de morarem em assentamentos com precárias condições financeiras. 
EID\&A - Revista Eletrônica de Estudos Integrados em Discurso e Argumentação, Ilhéus, n. 13, jan/jun.2017.

Ao apresentar a situação desses alunos mais carentes, L1 faz uso inicialmente de uma oração adjetiva [...] que passou QUINze VINte anos sem pegar numa caneta pra escrever nada...[...], que aqui funciona como modalizador avaliativo, tendo em vista a força expressivo-persuasiva resultante desse uso. Esse uso ressalta a ideia de que os alunos estão há muito tempo, há bastante tempo fora da sala de aula. Mais adiante, L1 faz uso de uma segunda oração adjetiva para opinar sobre a moradia desses alunos: [...] que moram em assentamentos...[...]. Na sequência, L1 utiliza uma terceira oração adjetiva [...] que chegam atrasados...[...], para argumentar sobre o não cumprimento de horário por parte desses alunos, considerando que não possuem recursos próprios para se deslocarem para a escola e, portanto, dependem de transporte mantido pela prefeitura, o qual não cumpre rigorosamente o horário de aulas.

Por último, para reforçar todo o argumento que vem sendo tecido desde o início deste trecho, L1 faz uso de uma quarta oração adjetiva que parece ser a justificativa mais forte, e, por isso, acaba se sobressaindo em relação às demais [...] que são da extrema pobreza MESmo...[...], cujo sentido retrata o fato de esses alunos fazerem parte da camada social mais carente e, portanto, são desprovidos de recursos financeiros. É possível perceber que L1 apresenta uma atitude de envolvimento, deixando evidente sua reação emotiva (CASTILHO; CASTILHO, 2002) diante dos fatos que avalia como negativos.

Essas orações adjetivas são restritivas, uma vez que especificam dados sobre os alunos, o que a priori poderiam não se constituir em elementos modalizadores ou apenas funcionarem como elementos modalizadores delimitadores. No entanto, também revelam um posicionamento sobre a situação social, econômica e pedagógica desses alunos. Por esse motivo, constituíram-se, nos enunciados em que aparecem, em elementos modalizadores avaliativos. Além disso, revelam ainda engajamento no enunciado, uma vez que L1 se compromete com o conteúdo ao manifestar explicitamente a sua opinião, criando, com isso, uma imagem clara a respeito do perfil do aluno da Escola Técnica.

Essa orientação argumentativa, materializada pelos modalizadores avaliativos em destaque, leva o candidato a professor (L2) a pensar em estratégias de ensino para conseguir trabalhar com esses diferentes perfis de alunos que compõem as salas de aula da instituição. Portanto, L1, ao orientar os recursos linguísticos nesse sentido, coloca L2 como alguém responsável 
EID\&A - Revista Eletrônica de Estudos Integrados em Discurso e Argumentação, Ilhéus, n. 13, jan/jun.2017.

para contribuir com o aprendizado de determinado público-alvo, que faz parte dos cursos técnicos da Unixy.

As orações destacadas, que funcionam como modalizadores discursivos, exercem, portanto, uma dupla orientação discursiva: (i) orientação de natureza avaliativa, uma vez que L1 expressam certo julgamento acerca do perfil dos alunos; e uma orientação de natureza delimitadora ou especificativa, pois L1 criam diferentes grupos de alunos, especificando o perfil de determinado grupo.

\section{MAV64-EE10-Linhas 09-13}

L2 [...] eu tenho pego várias preceptorias... lá na na secretaria... porque várias universidades estão:: ... é:: tendo mais curiosidade de saber qual o trabalho da gente e de... que que os alunos que estão se formando... conheçam o trabalho principalmente o trabalho da vigilância... então... SEMpre que tá... está tendo trabalho de preceptoria...

Como pode ser visto no trecho MAV64, é possível perceber o uso da expressão mais curiosidade como modalizador avaliativo. $O$ efeito de sentido dessa expressão recai, principalmente, sobre a expressão várias universidades, uma vez que se emite uma opinião a respeito das instituições de ensino, especificamente sobre o aumento na procura de preceptorias por parte dessas instituições junto à Secretaria Estadual de Saúde. L2, portanto, busca explicar que atualmente as universidades têm despertado mais para a valorização das práticas dos alunos e complementa essa explicação com uma avaliação positiva acerca desse aspecto.

Dando continuidade ao seu argumento, L2 utiliza também a expressão principalmente - sinônimo de "mais importante" -, que incide sobre o trabalho da vigilância, para enfatizar a sua avaliação, privilegiando a área de saúde nas preceptorias assumidas. Com esse modalizador, L2 apresenta também um engajamento com o dito, uma vez que elege a área da saúde, área da qual ele faz parte.

Na perspectiva dos estudos de Ducrot (1988), entende-se que, no caso em análise, a argumentação está inscrita na língua e encontra-se marcada nas escolhas linguísticas que o locutor faz ao produzir o enunciado. $\mathrm{O}$ valor argumentativo, portanto, não deriva de condições de verdade, e sim está inscrita na própria língua. E a língua, por sua vez, oferece ao usuário uma infinidade de possibilidades de construção e também uma série de limitações de uso. 
EID\&A - Revista Eletrônica de Estudos Integrados em Discurso e Argumentação, Ilhéus, n. 13, jan/jun.2017.

\begin{abstract}
MAV97-EE20-Linhas 58-63
L1 como é que você lida com esse perfil?

L2 olha... é bem complicado... assim... porque... por exemplo... eles não sabem que um ponto é multiplicação... então você tem que fazer um X... porque na época que eles estudaram era um X... eles não sabem que cinco sobre quatro é uma divisão... então... você tem que botar o o:: tudo você tem que adaptar a sua didática né? ao perfil do do [...]
\end{abstract}

O trecho MAV97 da EE20 representa parte da entrevista para o cargo de professor da disciplina de Contabilidade Empresarial para o curso técnico em Logística. É importante esclarecer que L2 havia comentado anteriormente que atua como tutora a distância na UFRN em um projeto que visa qualificar os servidores que estão fora da sala de aula há bastante tempo. Nesse projeto, ele ministra aula da disciplina de Estatística Básica. Portanto, o questionamento que $\mathrm{L} 1 \mathrm{faz}$ é a respeito do perfil desse grupo.

Podemos perceber que L2 usa a expressão é bem complicado para expressar sua opinião sobre o perfil dos alunos que não possuem uma formação básica necessária para acompanhar de modo razoável as aulas de disciplinas da área de exatas. Ao utilizar essa expressão, L2 traduz um julgamento subjetivo dos fatos, apresentando-os como negativos, ou seja, esses alunos desconhecem a linguagem atual da matemática e por isso [...] eles não sabem que um ponto é multiplicação... então você tem que fazer um X... porque na época que eles estudaram era um X...[...]. Assim, a expressão utilizada por L2 - é bem complicado - constitui-se em um modalizador avaliativo, pois revela um ponto de vista negativo do referido locutor acerca do conteúdo do enunciado.

\title{
MAV101-EE20-Linhas 89-101
}

L2 olhe... minha vida tinha tudo pra não ser o que é hoje... eu acho que tudo que eu tenho hoje em dia... tanto é... pessoal... material... espiritual... vem da da educação... né? porque eu busquei a educação como como minha fortaleza... então... eu acho que que a educação é extremamente importante... então... é dizer... falar de uma transformação... de você buscar a educação como como sei lá... como é que eu falo?

L1 suporte?

L2 não suporte... mas quebrar barreiras da pobreza... da ignorância... da falta de conhecimento... então... eu acho que é isso... dá como exemplo que tipo... eu podia não ter nada... meu pai é alcoólatra... minha mãe era era faxineira... entendeu? eu tinha tudo pra não ter nada do que tenho... mas graças a educação... a educação abriu horizontes pra mim... que eu nem poderia imaginar né? 
EID\&A - Revista Eletrônica de Estudos Integrados em Discurso e Argumentação, Ilhéus, n. 13, jan/jun.2017.

Ao construir um discurso em primeira pessoa, L2, nesse trecho da EE20, utiliza a expressão extremamente importante, que incide sobre a palavra educação, para registrar a sua opinião, explicitamente, a respeito dos benefícios que a educação trouxe para sua vida. Dessa forma, busca argumentar positivamente a esse respeito, demonstrando engajamento com o conteúdo da proposição ao defender a tese de que [...] tudo que eu tenho hoje em dia... tanto é... pessoal... material... espiritual... vem da da educação...[...].

O modalizador avaliativo - extremamente importante -, utilizado por L2, não só serve para imprimir um ponto de vista sobre o conteúdo do enunciado, nos termos em que postulam Nascimento \& Silva (2012), mas também para indicar a forma como L1 deve interpretar o enunciado de L2. Convém ressaltar ainda que $L 2$ utiliza os elementos linguísticos em destaque não apenas para falar da educação e exprimir um posicionamento pessoal a respeito, mas também para criar uma ideia positiva de si mesmo. Seu objetivo, na verdade, parece ser influenciar as decisões do entrevistador para que este leve em consideração o fato de ele ter "vencido na vida por meio dos estudos", o que pode servir de exemplo para os alunos do PRONATEC. Portanto, os elementos linguísticos destacados funcionam como modalizadores avaliativos. Por meio deles, L2 avalia e enfatiza as suas qualidades não só como educador, mas principalmente como vencedor, diante das dificuldades encontradas ao longo de sua formação, manifestando, assim, alta adesão com relação ao que diz.

Ademais, o trecho em destaque serve para ilustrar o modo como, na construção da entrevista, os interlocutores estão numa relação face a face, tendo o diálogo marcado pelas alternâncias, pelos turnos de fala. Geralmente, o final do turno da fala de L1 é marcado por uma pergunta. Por outro lado, L2 costuma marcar os finais de fala com uma afirmação, uma resposta, e dificilmente com uma pergunta, conforme exemplifica o trecho em questão. Mas isso não é unanimidade, tendo em vista os casos em que L2 faz perguntas retóricas com valor argumentativo durante a construção da resposta.

A partir dos postulados de Bakhtin (2011 [1979]), o primeiro traço fundamental do enunciado é a alternância dos sujeitos do discurso. Essa alternância abarca todos os enunciados, visto que todos eles têm um princípio absoluto e um fim absoluto, a saber: antes do seu início, os enunciados de outros; depois do seu término, os enunciados responsivos de outros. O enunciado é produzido em meio a outros enunciados, sendo produzido em 
EID\&A - Revista Eletrônica de Estudos Integrados em Discurso e Argumentação, Ilhéus, n. 13, jan/jun.2017.

diálogo com eles. Isso acontece porque todo enunciado, numa concepção bakhtiniana, nasce em resposta a outro enunciado e ao mesmo tempo convoca uma resposta subsequente.

O traço da alternância dos sujeitos do discurso "[...] cria limites precisos do enunciado nos diversos campos da atividade humana e da vida, dependendo das diversas funções da linguagem e das diferentes condições e situaç̃̃es de comunicação, e de natureza diferente e assume formas várias" (BAKHTIN, 2011 [1979], p. 275). Desse modo, a alternância dos sujeitos do discurso e a dinâmica relação entre os interlocutores (parceiros do diálogo) promovem limites entre enunciados. Tais limites funcionam como fronteiras que possibilitam a troca, o diálogo.

Cada enunciado, ou cada réplica, nos dizeres de Bakhtin (2011 [1979], p. 275), “[...] por mais breve e fragmentária que seja, possui uma conclusibilidade específica ao exprimir certa posição do falante que suscita resposta, em relação à qual se pode assumir uma posição responsiva". No caso do gênero entrevista de seleção de emprego, em alguns casos, a alternância de locutores é marcada por pequenos marcadores linguísticos.

\footnotetext{
MAV105-EE20-Linhas 148-156

L1 só mais uma coisa... com a sua experiência docente... você chegou a fazer plano de aula? plano de ensino?

L2 sim... assim... eu fui chamada numa sexta feira pra dá aula numa terça feira... né? ((riu))... mas aí... como eu já já é uma coisa que eu lido diariamente... já já vinha estudando... estou sempre estudando... então... foi bem mais fácil... mas aí... tudo depende do perfil do aluno... pra você planejar suas aulas... como é que vai ser a sua didática? como é que você vai fazer as avaliações... tudo isso... e também dos dos pré-requisitos da coordenação...
}

Nesse trecho da EE20, L1 deseja saber se L2 possui experiência com planejamento de aula. Visando responder a esse questionamento, L2 escolhe argumentar sobre a experiência que teve quando precisou elaborar, de última hora, um plano de aula para executá-lo em uma faculdade. Para tanto, utiliza a expressão bem mais fácil para avaliar que não considerou difícil executar essa tarefa, mesmo em um prazo curto.

A orientação argumentativa produzida pela expressão em destaque cria uma imagem positiva de L2, deixando implícito que ele não terá dificuldades para cumprir com essa atividade caso venha atuar na Unixy. Ou seja, L2 visa convencer o entrevistador de que possui capacidade para fazer plano de aula. 
EID\&A - Revista Eletrônica de Estudos Integrados em Discurso e Argumentação, Ilhéus, n. 13, jan/jun.2017.

Diante de ocorrências como essas, vale ressaltar a noção de valor argumentativo dos enunciados, conforme postula Ducrot (1988). Eis a explicação dada pelo autor:

El valor argumentativo de una palabra es por definición la orientación que esa palabra da al discurso. En efecto, a mi juicio el empleo de una palabra hace posible o imposible una cierta continuación del discurso y el valor argumentativo de esa palabra es el conjunto de esas posibilidades o imposibilidades de continuación discursiva que su empleo determina ${ }^{6}$. (DUCROT, 1988, p. 51).

Como se percebe, o valor argumentativo de uma palavra é entendido como sendo a orientação e as possibilidades de continuação que determinada palavra oferece ao discurso. Portanto, é pela orientação que a palavra dá ao discurso que se configura o seu valor argumentativo. Isso, evidentemente, é decorrente da tese desse linguista de que a argumentação está na língua. Vale salientar que Ducrot e colaboradores negam a ideia de que a língua tem primeiramente uma função referencial e que o sentido do enunciado se julgue em termos de verdade ou falsidade.

Desse modo, conforme os casos analisados corroboram, a argumentação reside nos recursos linguísticos, nas possiblidades de uso, nos movimentos de sentido que eles permitem realizar. Portanto, o valor argumentativo não se determina somente pelo fato expresso pelo enunciado, mas também pela forma linguística. A argumentação está marcada na própria língua (DUCROT, 1988).

Ademais, a língua é argumentativa em situações de uso. No caso das entrevistas, por exemplo, é a situação comunicativa, as pretensões dos participantes (entrevistado e entrevistador) e a própria estrutura do gênero entrevista que instauram orientações argumentativas para os recursos linguísticos.

Corroborando essa leitura, Espíndola (2004, p. 13), reescrevendo a tese original de Ducrot e colaboradores, afirma que não apenas a língua é argumentativa, mas "[...] língua e uso são fundamentalmente argumentativos". Em outras palavras, a língua deve ser estudada considerando não só a sua estrutura, mas também o seu uso e ambos são, por natureza, argumentativos.

${ }^{6} \mathrm{O}$ valor argumentativo de uma palavra é por definição a orientação que essa palavra dá ao discurso. De fato, ao meu ver o uso de uma palavra faz possível ou impossível uma certa continuação do discurso e o valor argumentativo dessa palavra é o conjunto dessas possibilidades ou impossibilidades de continuação discursiva que seu uso determina (Tradução nossa). 
EID\&A - Revista Eletrônica de Estudos Integrados em Discurso e Argumentação, Ilhéus, n. 13, jan/jun.2017.

\section{Considerações finais}

Com o objetivo de descrever e analisar o funcionamento linguísticodiscursivo dos modalizadores avaliativos, enquanto elementos que materializam a argumentatividade no gênero entrevistas de seleção de emprego, este trabalho analisou vinte e duas (22) entrevistas, gravadas em um Centro Universitário do Estado do Rio Grande do Norte, na cidade de Natal RN. Orientou-se pelas seguintes questões de pesquisa: (i) que modalizadores avaliativos são usados na construção do gênero entrevista de seleção de emprego?; e (ii) como tais modalizadores avaliativos são mobilizados de modo a construir a argumentatividade nas/das entrevistas?

Em resposta à primeira questão, a análise constatou que os interlocutores mobilizaram diferentes modalizadores discursivos nas entrevistas, especialmente sob a forma de adjetivos, advérbios, expressões adverbiais e orações adjetivas com função modalizadora. Numa perspectiva mais interpretativista, e considerando a segunda questão da pesquisa, constou-se o funcionamento argumentativo desses recursos na construção do gênero entrevista de seleção de emprego. Os modalizadores marcam pontos em que o locutor expressa juízo de valor ou apresenta uma justificativa a respeito do conteúdo proposicional.

Ademais, os modalizadores avaliativos aparecem em pontos em que 0 locutor pretende criar uma imagem positiva de sim mesmo, da instituição e mesmo do outro. Esse movimento visa ganhar a adesão do interlocutor ao seu ponto de vista, já que, conforme Koch (2010), o processo interacional é perpassado por ações, desejos, intenções, persuasão. Nesse jogo com a linguagem, os enunciados são dotados de determinada força argumentativa (KOCH, 2010).

Em síntese, a partir da perspectiva ducrotiana, o valor argumentativo de uma palavra é dado no enunciado. A argumentação reside na orientação e nas possibilidades de continuação que ela (determinada palavra) oferece ao discurso. Ducrot (1988) mostra que o valor argumentativo de uma palavra é o conjunto das possibilidades ou impossibilidades de continuação discursiva que seu uso determina. Portanto, é pela orientação que a palavra dá ao discurso que se configura o seu valor argumentativo.

O gênero entrevista de seleção de emprego é construído a partir de uma troca entre perguntas e respostas. Ele apresenta uma introdução com boasvindas aos entrevistados e uma breve apresentação dos objetivos pelos quais 
EID\&A - Revista Eletrônica de Estudos Integrados em Discurso e Argumentação, Ilhéus, n. 13, jan/jun.2017.

a instituição realiza a seleção. Traz na conclusão felicitações e agradecimentos por parte do entrevistador. Além disso, o estilo de linguagem acopla variantes do cotidiano e até aspectos mais formais - como o uso da linguagem acadêmica e empresarial.

Na perspectiva bakhtiniana, uma característica do enunciado concreto é que ele sempre une os participantes da situação comum como co-participantes que conhecem, entendem e avaliam a situação de maneira igual. $\mathrm{Na}$ entrevista, o ouvinte é entendido como aquele que o próprio locutor leva em conta, a quem um enunciado é orientado e que, por consequência, intrinsecamente determina a estrutura do enunciado. Logo, as perguntas que L1 faz durante a entrevista são elaboradas tendo em vista L2. Mesmo que tenham sido elaboradas previamente, como é comum ocorrer nessa situação de interação verbal, tais perguntas são construídas porque L1 leva em conta o outro, L2. É importante destacar que, mesmo durante o processo de troca, as perguntas podem ser reformuladas, dependendo da participação de L2 no próprio processo de interação, em função da atitude responsiva do outro.

\section{Referências}

ADELINO, Francisca Janete da Silva. Na trilha dos modalizadores: perscrutando os jogos argumentativos no gênero entrevista de seleção de emprego. 2016. Tese (Doutorado em Linguística). Universidade Federal da Paraíba, João Pessoa, 2016.

BAKHTIN, Mikhail Mikhailovitch. Estética da criação verbal. 6.ed. Introd. e trad. do russo de Paulo Bezerra. São Paulo: WMF Martins Fontes, 2011 [1979].

CASTILHO, Ataliba Teixeira; CASTILHO, Célia Moraes. Advérbios Modalizadores. In: ILARI, Rodolfo (Org.). Gramática do Português Falado. v. 2. 2.ed. Campinas: Ed.UNICAMP, 2002. p. 199-247.

DUCROT, Oswald. Polifonia e argumentação: Conferencía del SeminárioTeoria de la Argumentación y Analisis del Discurso. Cali, Universidad del Valle, 1988.

ESPÍNDOLA, Lucienne Claudete. A entrevista: um olhar argumentativo. João Pessoa: EDUFPB, 2004.

$\mathrm{KOCH}$, Ingedore Grunfeld Villaça. A inter-ação pela linguagem. 10.ed. São Paulo: Contexto, 2010.

. Argumentação e Linguagem. 13.ed. São Paulo: Cortez, 2011. 
EID\&A - Revista Eletrônica de Estudos Integrados em Discurso e Argumentação, Ilhéus, n. 13, jan/jun.2017.

NASCIMENTO, Erivaldo Pereira do. Jogando com as vozes do outro: a polifonia recurso modalizador - na notícia jornalística. Tese (Doutorado em Linguística). Universidade Federal da Paraíba, João Pessoa, 2005.

. Os gêneros do discurso e os manuais de redação comercial e oficial. In: NASCIMENTO, Erivaldo Pereira do (Org.). A Argumentação na Redação Comercial e Oficial: Estratégias Semântico-Discursivas em Gênero Formulaicos. João Pessoa: Editora Universitária da UFPB, 2012. p. 25-27.

NASCIMENTO, Erivaldo Pereira do; SILVA, Joseli Maria da. O fenômeno da Modalização. In: NASCIMENTO, Erivaldo Pereira do. A redação comercial oficial: estratégias semântico-discursivas em gêneros formulaicos. João Pessoa, Editora Universitária/UFPB, 2012. p. 63-100.

NEVES, Maria Helena de Moura. Texto e Gramática. 3.ed. São Paulo. Contexto, 2011.

Forma de citação sugerida:

ADELINO, Francisca Janete da Silva; NASCIMENTO, Erivaldo Pereira do. A orientação argumentativa dos modalizadores avaliativos. EID\&A - Revista Eletrônica de Estudos Integrados em Discurso e Argumentação, Ilhéus, n. 13, p. 18-35, jan/jun.2017.

Recebido em: 24/02/2017

Aprovado em: 20/05/2017 